\title{
Management of Internal Resorption with Perforation
}

\author{
${ }^{1}$ Mahendran Kavitha, ${ }^{2} \mathrm{~K}$ Girija, ${ }^{3}$ Shekar Shobana
}

\begin{abstract}
Internal root resorption is a pathologic intraradicular process in which there is loss of dental hard tissue due to osteoclastic activity inside the root canal space. It is a rare lesion of permanent teeth, which might be caused due to caries, trauma, restorative procedures, etc. Because of its insidious pathology, it can extend to significant dimensions before being diagnosed and may lead to perforation to external root surface due to progressive odontoclastic activity. This article describes two case reports of surgical management of a perforating internal resorption in maxillary central incisors, managed by routine root canal treatment, followed by repair with Biodentine and mineral trioxide aggregate (MTA). About 12 to 24 months of follow-up demonstrated clinically asymptomatic and adequately functional tooth, with radiographic signs of healing. Care was taken to conserve the tooth structure and avoid further weakening of the alreadycompromised tooth. A tooth deemed to have a questionable prognosis was conserved and found to demonstrate satisfactory healing with no radiographic evidence of progressive resorption.
\end{abstract}

Keywords: Biodentine, Internal resorption, Mineral trioxide aggregate, Osteoclastic activity, Perforation, Thermoplasticized obturation.

How to cite this article: Kavitha M, Girija K, Shobana S. Management of Internal Resorption with Perforation. J Oper Dent Endod 2018;3(1):38-42.

Source of support: Nil

Conflict of interest: None

\section{INTRODUCTION}

Internal resorption is an inflammatory condition that results in progressive destruction of intraradicular dentin and dentinal tubules along the middle and apical thirds of the canal walls. ${ }^{1}$ It is stated that trauma and pulpal inflammation/infection are the major contributory factors in the initiation of internal resorption. ${ }^{1}$ For internal root resorption to occur, the outermost protective odontoblast layer and the predentin of the canal wall must be damaged, resulting in exposure of the underlying mineralized dentin to odontoclasts. ${ }^{2}$ The progression of

\footnotetext{
${ }^{1}$ Professor and Head, ${ }^{2,3}$ Postgraduate Student

${ }^{1-3}$ Department of Conservative Dentistry and Endodontics, Tamil Nadu Government Dental College and Hospital, Tamil Nadu Dr. M. G. R. Medical University, Chennai, Tamil Nadu, India
}

Corresponding Author: Mahendran Kavitha, Professor and Head, Department of Conservative Dentistry and Endodontics Tamil Nadu Government Dental College and Hospital, Tamil Nadu Dr. M. G. R. Medical University, Chennai, Tamil Nadu, India e-mail: kavithaendo@yahoo.com internal resorption depends on vital tissues. ${ }^{3}$ Therefore, root canal treatment should be initiated as soon as possible once an inflammatory resorptive lesion is detected in order to prevent further hard tissue loss and eventually root perforation. In cases without a perforation, the removal of the granulation tissue and the blood supply to the resorbing cells by root canal treatment should be sufficient. However, in cases in which a pathway between the pulp canal space and the periodontal tissues is present, root canal treatment should be followed by repair of the perforation site with a suitable sealing biomaterial. ${ }^{4}$

\section{CASE REPORTS}

\section{Case 1}

\section{Clinical Examination}

A 19-year-old female patient reported to the department with the chief complaint of recurrent dull-aching pain in the upper front tooth for past 2 weeks and discoloration with intermittent pus discharge into the labial vestibule. She had history of trauma 5 years back, and underwent root canal treatment in a private dental clinic 1 month back. On clinical examination, 21 showed brownish discoloration with class IV composite restoration on distal aspect (Fig. 1) and 11 had class II Ellis fracture; 21 was tender on percussion. The pulp sensibility test showed no response in 21 and normal response in 11, 22.

\section{Radiographic Examination}

The radiographic findings showed incomplete obturation and ballooning radiolucency of root canal wall of 21 .

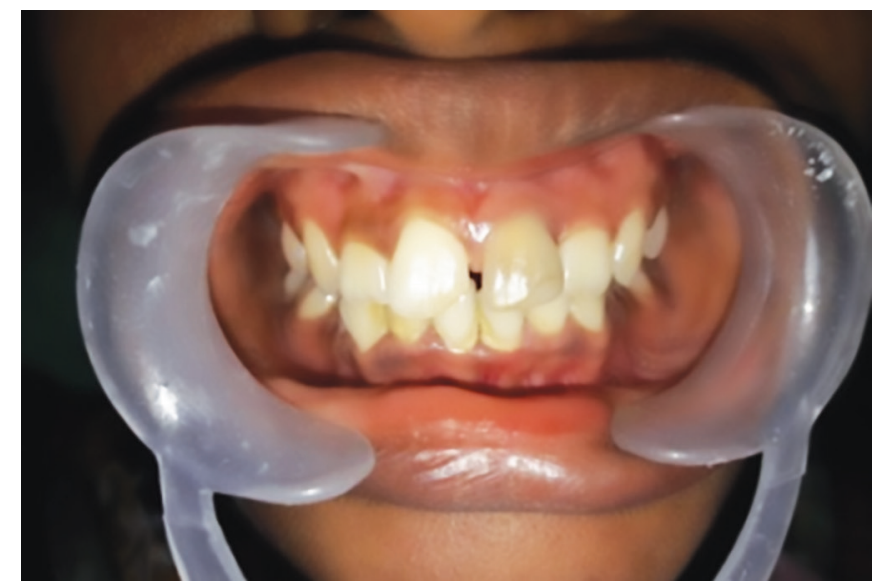

Fig. 1: Preoperative image showing brownish discoloration with composite restoration on distal aspect of 21 


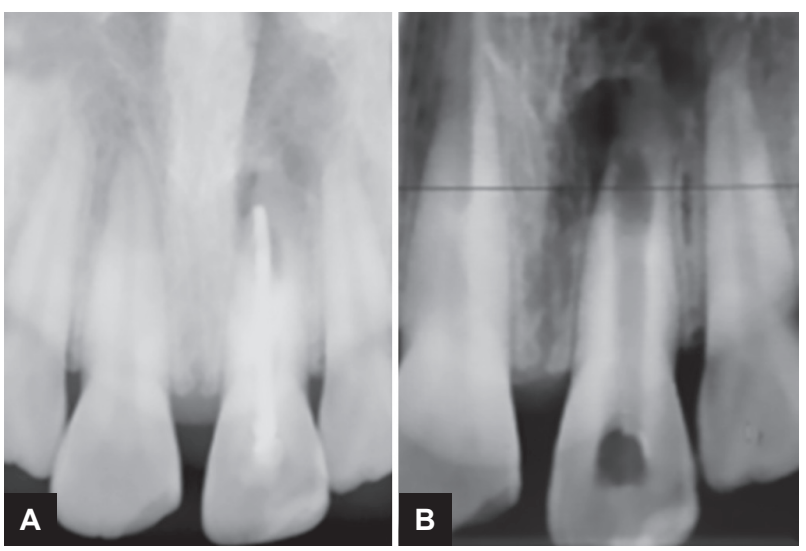

Figs 2A and B: (A) Preoperative radiograph showing incomplete obturation in 21. (B) Radiograph showing ballooning radiolucency of root canal wall of 21 and associated periapical radiolucency with thinned out wall on mesial aspect of root of 21

There was also periapical radiolucency with thinned out wall on mesial aspect of root of 21 (Fig. 2).

\section{Diagnosis}

The case was diagnosed as previously treated 21 associated with internal resorption and symptomatic apical periodontitis.

\section{Treatment Plan}

The treatment plan is shown in Flow Chart 1.

\section{Treatment Procedure}

An informed consent from the patient was taken. The root canal retreatment was initiated under rubber dam isolation in 21. The access cavity was redefined using Endo Access Bur and gutta-percha was retrieved. Bleeding from canal was present. Calcium hydroxide dressing was given for initial two appointments at an interval of 10 days. The root canal of 21 was then obturated using customized guttapercha and Endoseal MTA sealer (ENDOCEM, Maruchi Products). After completion of root canal treatment, the surgical procedure ensued. A full-thickness mucoperiosteal triangular flap was elevated extending from mesial of 23 to distal of 12 . The overextended gutta-percha through the perforation site at the apical third of root of 21 was identified and removed (Fig. 3A). Curettage was done followed by root end resection up to the perforation site (Fig. 3B), retrograde preparation, and retrograde filling with MTA (Angelus Solucoes Odontologicas, Londrina, PR, Brazil) (Figs 3C and 4). The flap was repositioned and sutured back. After 3 months, a metal ceramic crown was
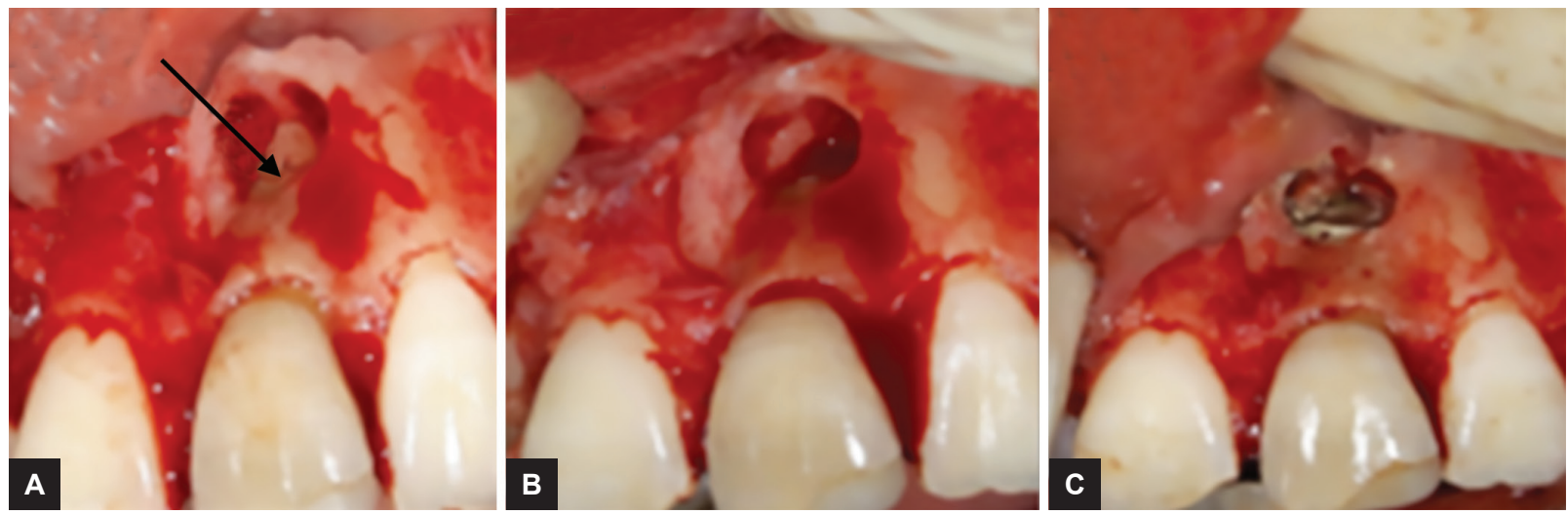

Figs 3 A to C: (A) Overextended gutta-percha in apical third of root of 21 (shown by black arrow). (B) Root end resection done up to the perforation site in 21. (C) Retrograde preparation followed by retrograde filling done with MTA in 21

Flow Chart 1: Treatment plan for case 1
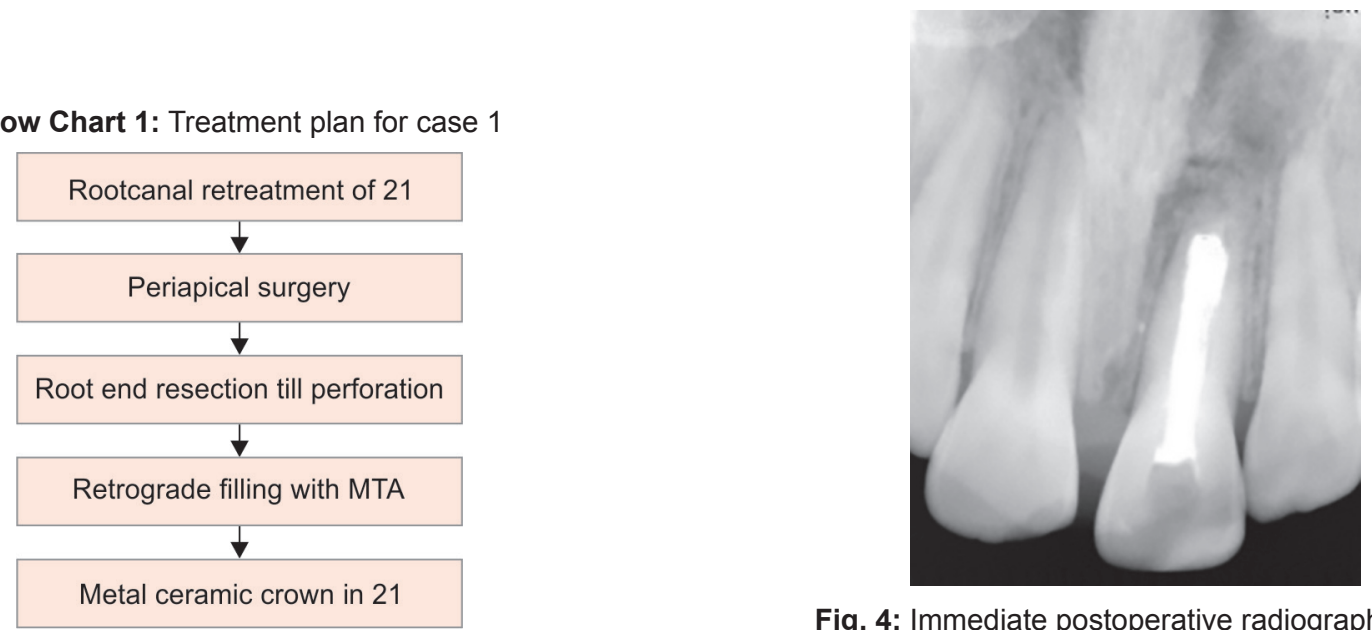

Fig. 4: Immediate postoperative radiograph of 21 


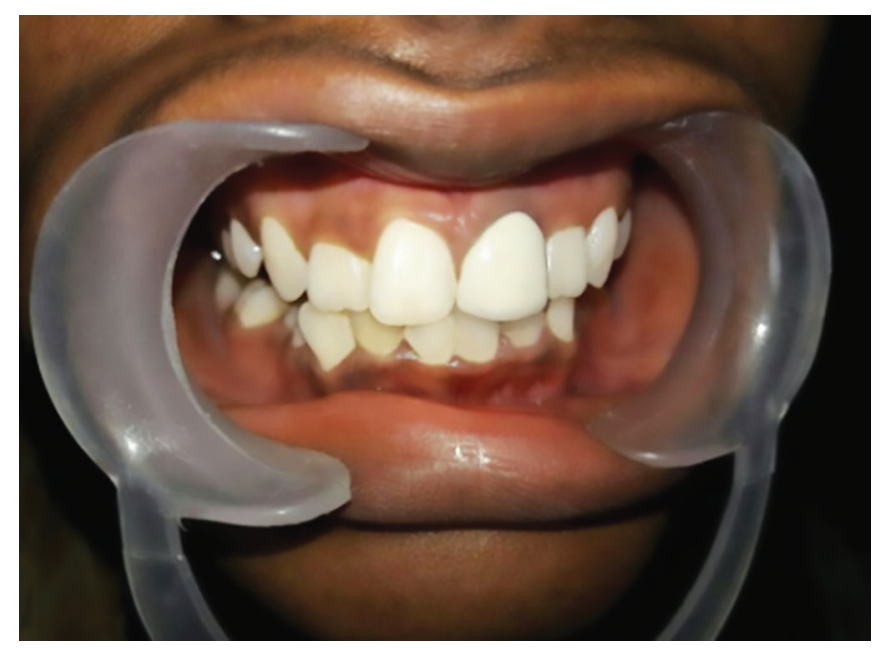

Fig. 5: Restoration of 21 with metal-ceramic crown

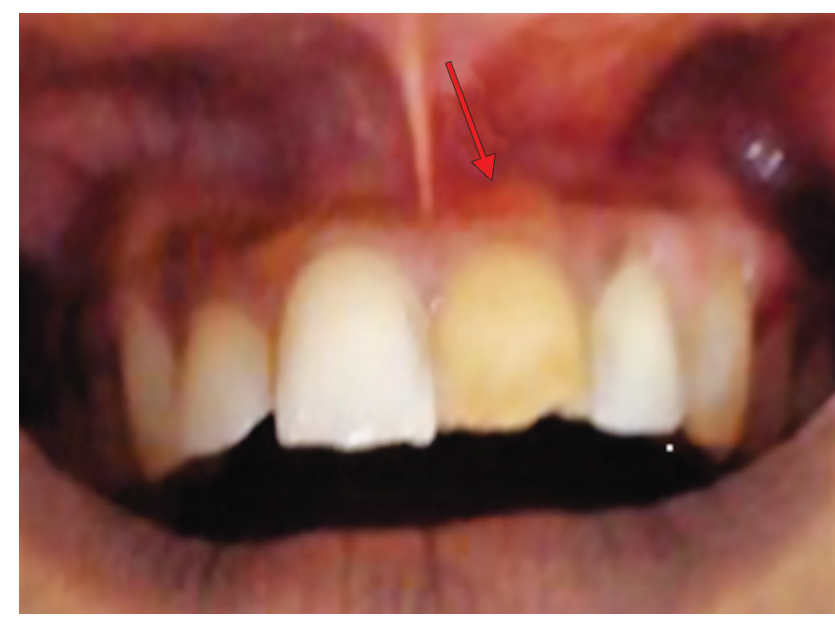

Fig. 7: Preoperative image showing discolored 21 with redness of the alveolar mucosa and a draining sinus tract (shown by red arrow)

given as postendodontic restoration (Fig. 5). At the end of 1 year, the patient was completely asymptomatic with radiographic evidence of healing (Fig. 6).

\section{Case 2}

\section{Clinical Examination}

A 40-year-old female patient reported to the department with the chief complaint of dull aching pain since 3 weeks and discoloration of upper front tooth. Patient had a history of trauma 4 years ago followed by a gradual change in color of tooth. Patient had undergone root canal treatment in a private dental clinic a week ago. Intraoral examination revealed previously root canal treated and discolored 21 with redness of the alveolar mucosa and a draining sinus tract in relation to 21 (Fig. 7). On probing, the periodontal probing depth on the labial aspect of 21 was $7 \mathrm{~mm}$ with extrusion of gutta-percha through the gingival sulcus. Radiographic investigation revealed the presence of radiopacity in the root canal of 21 extending beyond the radiographic apex. There was a characteristic hour glass-shaped radiopacity in the middle third of the root of 21 (Fig. 8).

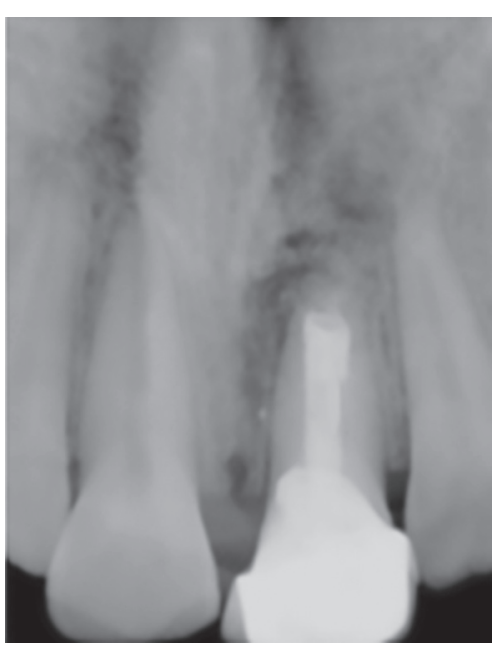

Fig. 6: Follow-up radiograph at the end of 1 year

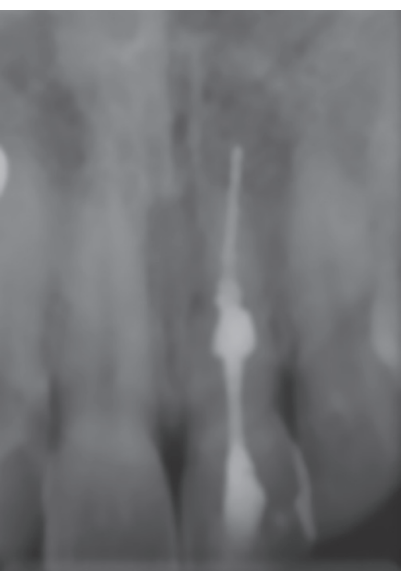

Fig. 8: Preoperative radiograph showing presence of radiopacity in the root canal of 21 extending beyond the radiographic apex with characteristic hour glass-shaped radiopacity in the middle third of the root of 21

\section{Diagnosis}

Correlating the clinical and radiographic findings, the case was provisionally diagnosed as previously treated 21 with perforating internal inflammatory resorption and symptomatic apical periodontitis.

\section{Treatment Plan}

The treatment plan is shown in Flow Chart 2.

Flow Chart 2: Treatment plan for case 2

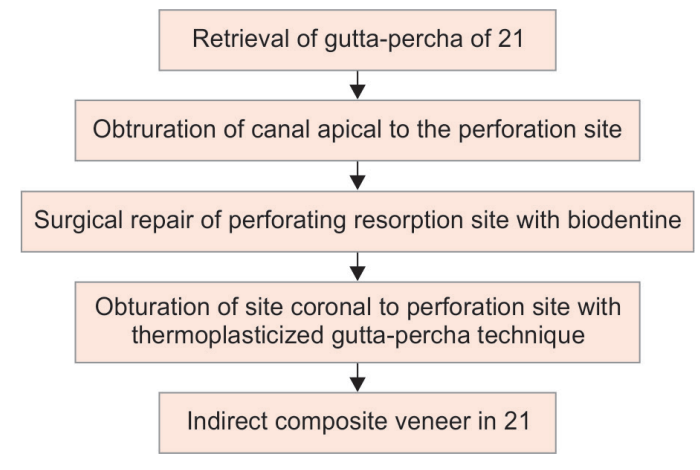



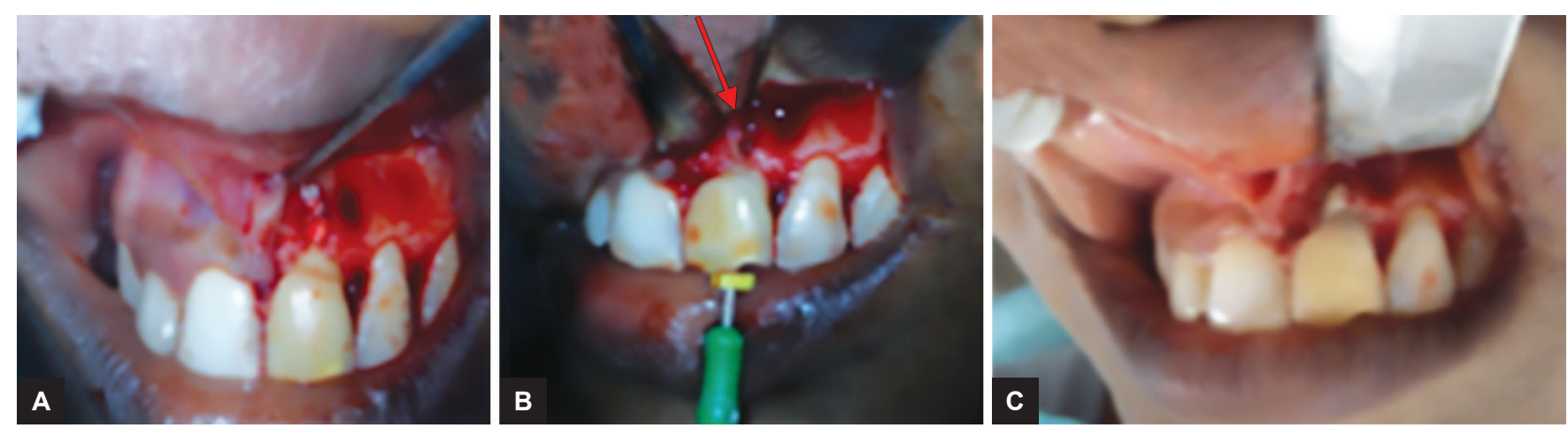

Figs 9A to C: (A and B) Identification of perforation site at the middle third of 21 root (shown by red arrow). (C) Repair of perforation site of 21 with biodentine (Septodont)

\section{Treatment Procedure}

Under rubber dam isolation, access was regained in 21 and gutta-percha was retrieved. The canal was irrigated with $3 \%$ sodium hypochlorite, and intracanal $\mathrm{Ca}(\mathrm{OH})_{2}$ dressing was placed to arrest the inflammatory process and induce repair. Full-thickness mucoperiosteal flap was raised in relation to 21 , and perforation site identified in the middle third of root measuring $2 \mathrm{~mm}$ in diameter (Figs 9A and B). The granulation tissue was curetted from perforation site, and apical third of the canal was obturated with master cone of 60 size $2 \%$ gutta-percha. Followed by this, the perforation site was repaired using Biodentine (Septodont) (Fig. 9C) and the flap was sutured back in position. Remaining canal was obturated with thermoplasticized gutta-percha (Fig. 10); 21 was restored with indirect composite veneer (Fig. 11) after 1 month. After a follow-up period of 24 months, 21 was asymptomatic clinically and radiographically.

\section{DISCUSSION}

Internal resorption is an insidious pathological process, remains dormant, unless it is associated with significant pulpal inflammation or communication with periodontal ligament space. Even though etiology remains idiopathic,

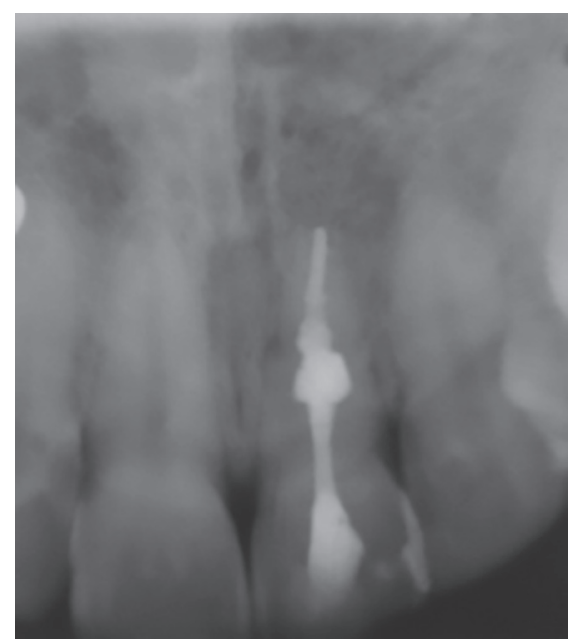

Fig. 10: Immediate postoperative radiograph

it can be concluded that trauma and associated pulpal inflammation/infection are the major contributory factors in the initiation of internal resorption, the radiological finding which shows an increase in radiolucent space within the root canal space and contiguous with root canal wall outline, clinician can substantiate his/her diagnosis. The treatment of internal resorption is quite challenging because of the irregular confines of the resorption cavity, presence of granulation tissue, and inaccessibility to
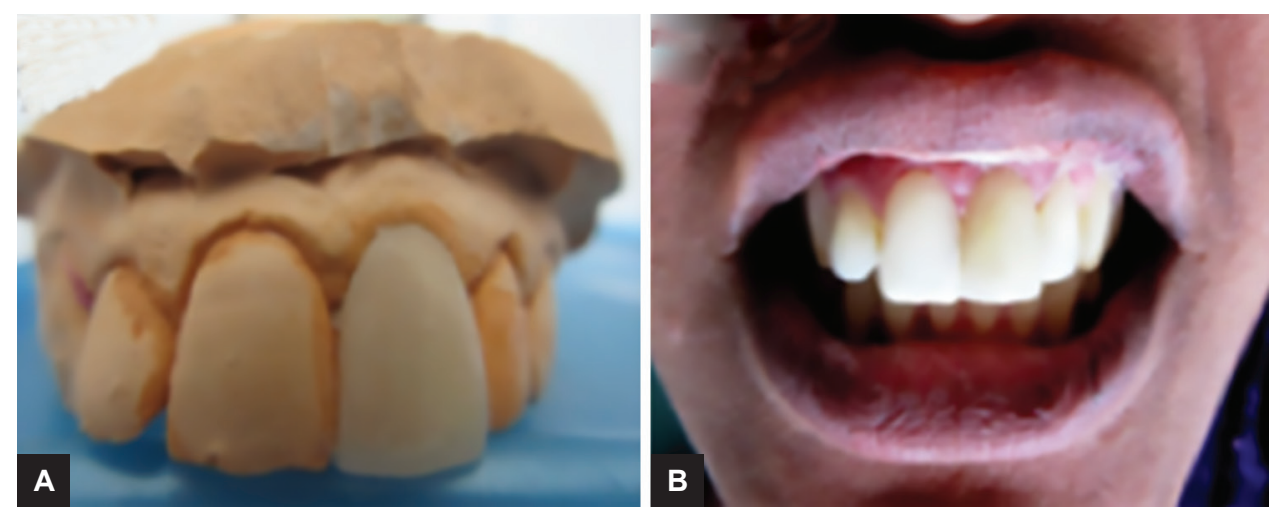

Figs 11A and B: (A) Indirect composite veneer fabricated on 21. (B) Clinical photograph showing 21 restored with indirect composite veneer 
direct mechanical instrumentation. ${ }^{1}$ The gold standard treatment consists of debridement and obturation of pulp space, sealing of external communication, and restoration of normal function of tooth through nonsurgical or surgical method. ${ }^{5}$

Both cases had a similar history and clinical findings, namely, yellowish brown discoloration of tooth associated with a draining sinus and a history of traumatic injury. Perforation was identified by correlating the clinical and radiologic findings. When diagnosed, immediate removal of the causative agent must be considered, aiming to arrest the cellular activity responsible for the resorptive activity. ${ }^{6}$ Calcium hydroxide between sessions was aimed at dissolving remaining pulpal debris, alkalinizing the environment, and controlling periodontal bleeding. ${ }^{7}$ Root perforation can be managed either surgically or nonsurgically, and the choice depends upon the accessibility and visibility of the perforation area, duration and size, patient's oral hygiene, and periodontal condition. ${ }^{4}$

In case report 1, the location of perforation was in the apical area of the root, and repair was planned surgically after obturation of canal space. Endoseal MTA was used as a sealer along with customized gutta-percha for obturation. The novel sealer Endoseal MTA is based on MTA and had comparable sealing ability to a proprietary brand sealer cement. In contact with a simulated body fluid, the MTA sealer released calcium ions in solution that encouraged the deposition of calcium phosphate crystals. ${ }^{8}$ It is available in paste-type, premixed, and preloaded in a syringe that allows direct application of the sealer into the root canal without requiring powder/liquid mixing. Since perforation was in nonesthetic area, MTA was used as repair material, which results in new cementum formation and periodontal regeneration, despite its extrusion into periradicular tissues. ${ }^{9}$ Set MTA can acquire its optimal strength and produce excellent sealability in the inherently wet environment of the perforation. ${ }^{9}$

In case report 2, repair of defect at cervical third of the root was done surgically before obturation of canal. Since defect was more towards esthetic area, Biodentine was preferred to be used as repair material. It is known as dentin in a capsule, a biocompatible and bioactive dentin substitute, which overcomes the drawbacks of calcium hydroxide and MTA. Biodentine holds promise for clinical dental procedures as a biocompatible and easily handled product with less cost and short setting time. Thermoplasticized gutta-percha was used to fill the reminiscent portion of the canal due to the passivity of the technique.

\section{CONCLUSION}

The clinician's ability to detect this pathologic entity must rely heavily on the use of radiographs in routine oral examination. Early detection and a correct differential diagnosis are essential for successful management of internal resorption to reinforce the remaining root structure and effectively seal the root perforation. The use of bioceramic material in the management of perforation will accomplish both the above objectives effectively.

\section{REFERENCES}

1. Patel S, Ricucci D, Durak C, Tay F. Internal root resorption: a review. J Endod 2010 Jul;36(7):1107-1121.

2. Trope M. Root resorption of dental and traumatic origin: classification based on etiology. Pract Periodontics Aesthet Dent 1998 May;10(4):515-522.

3. Thomas P, Krishna Pillai R, Pushparajan Ramakrishnan B, Palani J. An insight into internal resorption. ISRN Dent 2014 May;2014:759326.

4. Saed SM, Ashley MP, Darcey J. Root perforations: aetiology, management strategies and outcomes. The hole truth. Br Dent J 2016 Feb;220(4):171-180.

5. Li FC, Hung WC. Repair of a perforating internal resorption: two case reports. J Dent Sci 2016 Sep;11(3):338-342.

6. Trope M. Root resorption due to dental trauma general principles. Endod Top 2002 Mar;1(1):79-100.

7. Jacobovitz M, de Lima RK. Treatment of inflammatory internal root resorption with mineral trioxide aggregate: a case report. Int Endod J 2008 Oct;41(10):905-912.

8. Camilleri J, Gandolfi MG, Siboni F, Prati C. Dynamic sealing ability of MTA root canal sealer. Int Endod J 2011 Jan;44(1):9-20.

9. Lee SJ, Monsef M, Torabinejad M. Sealing ability of a mineral trioxide aggregate for repair of lateral root perforations. J Endod 1993 Nov;19(11):541-544. 